\title{
Freezing properties of alkenyl succinic anhydrides derived from linear isomerised olefins
}

Philip B. Sellars ${ }^{\S \dagger^{*}}$, Leo Lue $\S^{\S}$, Iain S. Burns ${ }^{\S}$ and D. Neil Work ${ }^{\diamond}$

$\S$ Department of Chemical \& Process Engineering, University of Strathclyde, James Weir Building, 75 Montrose Street, Glasgow, G1 1XJ, United Kingdom

$\diamond$ Pentagon Fine Chemicals, Lower Road, Halebank, Widnes, WA8 8NS, United Kingdom

KEYWORDS: Alkenyl succinic anhydride, olefin isomer distribution, GC, freezing temperature, melting temperature.

ABSTRACT: Alkenyl succinic anhydrides are important specialty chemicals that are used in the paper, oilfield and fuel additives industries. In this paper we investigate the link between the physical properties of alkenyl succinic anhydrides and the identities of their linear alkyl olefin precursors. We describe a straightforward GC analysis of olefin isomer distributions and show that these correlate well with the freezing temperatures of the subsequent alkenyl succinic anhydride products. This allows the identification of olefin isomer profiles that are required to give the desired physical properties in the alkenyl succinic anhydrides; it also provides a method to predict the freezing temperatures of alkenyl succinic anhydrides synthesised from a particular supply of olefin. 


\section{INTRODUCTION}

Alkenyl succinic anhydrides (ASAs) are used as sizing agents in the paper industry and also find use in the drilling of oil wells and as fuel additives. ${ }^{1,2}$ ASAs are formed by an Alder-ene reaction of a linear alkyl olefin and maleic anhydride. ${ }^{3}$ It is widely known that isomerised olefins give ASAs with lower freezing temperatures - ASA from C-18 $\alpha$-olefin is a solid at temperatures below about $16^{\circ} \mathrm{C}$. The lower freezing temperatures of ASAs produced from isomerised olefins mean that they remain liquid at ambient temperatures, making their handling easier in paper mills, where an emulsion of ASA is made and added to paper pulp. ${ }^{1,4}$ Despite the practical importance of ASAs, there are few studies on the details of the link between the nature of the olefin isomers and the resulting properties of the ASAs. Key to being able to study this link is the ability to characterise the distribution of double bond positions along the linear olefin chain.

Soják et al. developed a GC method that allowed the identification of isomers of moderatelength linear alkyl olefins. ${ }^{5}$ However, while peak separation was good enough to identify the individual isomers, the liquid crystal columns used in the work were specially designed for the purpose and are not commercially available. An alternative column using a $\mathrm{C}_{87}$ stationary phase required GC runs that were 2 hours long. ${ }^{6}$

Gee and Prampin carried out cross metathesis reactions of olefins using the Grubbs II catalyst and used a custom computer algorithm to estimate the double bond distribution from GC analyses of the metathesis products. ${ }^{7}$ Kim et al. also used cross metathesis reactions of olefins, with methyl acrylate or 2-methyl-2-butene, and GC-MS or LC-MS analysis to determine isomer distribution. ${ }^{8}$ However, mixtures of olefins (rather than a single isomer) could lead to cross metathesis of olefins with unknown double bond positions, making identification problematic. 
Wheeler and co-workers carried out derivatisation of nonene isomers in a Friedel-Crafts reaction with phenol. ${ }^{9}$ GC analysis of the resultant products allowed identification of the different isomers, but in our systems (typically octadecene or hexadecene for paper sizing ASAs) there is likely to be a larger number of derivatised products, making the GC analysis more difficult. In addition, the Friedel-Crafts reaction generates a carbocation on the olefin, which can lead to isomerisation, so the derivatised product may not be representative of the olefin's isomer distribution.

Chapman and Kuemmel investigated the double bond position of linear olefins by separating cis- and trans- isomers using liquid chromatography on silver nitrate-impregnated alumina and carrying out oxidative cleavage of the double bond using a periodate-permanganate method. ${ }^{10}$ The carboxylic acid products were converted to the methyl esters before analysis using GC to determine the chain lengths of the fragments.

All of these methods require further preparative steps before analysis, which are not ideal for process control in commercial production situations. In addition, the only method of ASA freezing temperature determination reported was using differential scanning calorimetry (DSC), ${ }^{11}$ which is a technique that may not be available on all manufacturing sites.

One of the main aims of this work was to find a simple and relatively quick method to estimate the freezing temperature of an ASA from the isomer distribution in its starting olefin. In this work we present a method to characterise this isomer distribution and a method to determine the freezing temperature of ASAs, before examining the relationship between these two quantities.

\section{EXPERIMENTAL SECTION}

2.1 Materials. Linear C-18 $\alpha$-olefins were supplied by Shell Chemicals (Rotterdam, Netherlands) and INEOS Oligomers (Feluy, Belgium). The olefins from the different suppliers 
contained varying amounts of vinyl and vinylidene olefins: Shell (vinyl alpha $=92.7 \%$, branched + internal $=7.2 \%)$, INEOS $($ vinyl $=53.4 \%$, vinylidene $=36.7 \%)$. Sodium oxide on alumina was supplied by SiGNa Chemistry (New York, NY, USA); sulfonic acid resins were supplied by Purolite (Bala Cynwyd, PA, USA) - wet resins were dried in a $110^{\circ} \mathrm{C}$ oven prior to use. Zeolite Y was obtained from Alfa Aesar (Ward Hill, MA, USA), Bentonite clay K-10 and maleic anhydride from Acros Organics (Geel, Belgium), and iron pentacarbonyl from Sigma Aldrich (St. Louis, MO, USA).

2.2 Isomerisation of linear $\boldsymbol{\alpha}$-olefins. Solid catalysts were added to the olefin at ambient temperature then heated to $25-200{ }^{\circ} \mathrm{C}$. In iron pentacarbonyl reactions the olefin was heated to 140-200 ${ }^{\circ} \mathrm{C}$ before addition of iron pentacarbonyl via syringe. All reactions were monitored by IR absorption spectroscopy; reduction in intensity of $\alpha$-olefin signals (and consequent increase for isomerised olefin signals) showed the progression of reactions. Reactions were deemed to be complete when the ratio of peak heights for internal olefin $\left(964 \mathrm{~cm}^{-1}\right)$ :vinyl $\alpha$-olefin $\left(908 \mathrm{~cm}^{-1}\right)$ was at least 9:1. Solid catalysts were removed from the olefin by filtration. A selection of reaction conditions is as follows (characterisation data for which can be found in Table 1): A: Shell olefin, $\mathrm{NaO}$-alumina $(4 \mathrm{wt} \%), 60^{\circ} \mathrm{C}, 2 \mathrm{~h}$; B: Shell olefin, Bentonite clay K-10 (2 wt $\%$ ), $140^{\circ} \mathrm{C}, 8 \mathrm{~h}$; C: Shell olefin, Bentonite clay K-10 (2wt\%), $160{ }^{\circ} \mathrm{C}, 9$ h; D: Shell olefin, Zeolite Y (2 wt\%), $200{ }^{\circ} \mathrm{C}, 10.5$ h; E: Shell olefin, Purolite CT151DR (2.3 wt\%), $200{ }^{\circ} \mathrm{C}, 3 \mathrm{~h}$; F: Shell olefin, Purolite CT169 (2 wt\%), $120^{\circ} \mathrm{C}, 2.5$ h; G: INEOS olefin, Purolite CT169 (2 wt\%), 120 ${ }^{\circ} \mathrm{C}, 2.5 \mathrm{~h}$; H: Shell olefin, Iron pentacarbonyl (0.15 mol\%), $150{ }^{\circ} \mathrm{C}, 4.75 \mathrm{~h}$; I: INEOS olefin, Iron pentacarbonyl $(0.15 \mathrm{~mol} \%), 150{ }^{\circ} \mathrm{C}, 12 \mathrm{~h}$.

2.3 Synthesis of ASAs. Isomerised C-18 linear olefin (60 g, $0.24 \mathrm{~mol})$ and maleic anhydride (14.6 g, $0.15 \mathrm{~mol})$ were heated to $220{ }^{\circ} \mathrm{C}$ under $\mathrm{N}_{2}$ in a three-necked flask fitted with a 
mechanical stirrer and a reflux condenser. The reaction was kept at this temperature for 6 hours then distilled under reduced pressure (1 mbar) to remove unreacted maleic anhydride and excess olefin.

2.4 GC analysis. Gas chromatography was used to determine the distribution of double bond positions in the isomerised olefins. The method employed for GC analysis of the isomerised olefin samples was derived from a method described by Reddy et al. ${ }^{12}$ Analysis was carried out on a PerkinElmer (Waltham, MA, USA) XL gas chromatograph fitted with a Phenomenex (Torrance, CA, USA) Zebron ZB-1 or Agilent (Santa Clara, CA, USA) J\&W DB-1 capillary column (60 m, $0.32 \mathrm{~mm}$ i.d., $0.25 \mu \mathrm{m}$ film thickness). Nitrogen was used as the carrier gas (14 psi) with an injector temperature of $350^{\circ} \mathrm{C}$ and a FID temperature of $300^{\circ} \mathrm{C}$. The olefin sample was diluted 1:5 in cyclohexane and tested on a temperature program that was: isothermal at 145 ${ }^{\circ} \mathrm{C}$ for $20 \mathrm{~min}$; ramped at $0.7^{\circ} \mathrm{Cmin}^{-1}$ to $160{ }^{\circ} \mathrm{C}$; isothermal at $160{ }^{\circ} \mathrm{C}$ for $5 \mathrm{~min}$; ramped at 10 ${ }^{\circ} \mathrm{Cmin}^{-1}$ to $300{ }^{\circ} \mathrm{C}$; isothermal at $300^{\circ} \mathrm{C}$ for $25 \mathrm{~min}$.

2.5 Lab freezing temperature determination. A simple method to determine the freezing temperature works on the principles outlined by Ross and Glasgow, ${ }^{13}$ but the equipment set-up is a simplified version of apparatus described in a PHYWE Systeme test method, ${ }^{14}$ designed to allow implementation with standard components in an analysis lab at an industrial site. A sample of about $10 \mathrm{~g}$ of olefin or ASA was placed in a test tube $(2 \mathrm{~cm} \times 14.5 \mathrm{~cm})$, giving a depth of about $3 \mathrm{~cm}$ of sample. This test tube was stoppered with a size 49 Suba-seal, through which a low-temperature thermometer $\left(-60\right.$ to $\left.30^{\circ} \mathrm{C}\right)$ was held in the sample. The test tube sat inside a boiling tube $(3 \mathrm{~cm} \times 20 \mathrm{~cm})$ that was cooled using an acetonitrile- $\mathrm{CO}_{2}$ mixture - this gives a temperature of around $-40{ }^{\circ} \mathrm{C}$, allowing sufficient cooling to reach the freezing temperatures of the ASAs - while the air gap between the boiling tube and test tube ensured uniform cooling of 
the sample (which is stirred using a magnetic stirrer bar). ${ }^{13}$ The freezing temperature was taken as the value where the temperature remained constant (i.e. had ceased to decrease), similar to the situation described by Hoare for a material that is not subjected to supercooling. ${ }^{15}$

2.6 DSC melting temperature determination. DSC was also used to determine the melting temperatures of ASA samples. The method for DSC was based on that outlined by Vaca-Garcia et al. ${ }^{16}$ Analysis was carried out using a TA Instruments (New Castle, DE, USA) DSC Q20 machine. A sample of ASA (15-20 mg) in a sealed aluminium pan was equilibrated at $30^{\circ} \mathrm{C}$ for 5 minutes, cooled at $10{ }^{\circ} \mathrm{Cmin}^{-1}$ to $-50{ }^{\circ} \mathrm{C}$ then heated at $10{ }^{\circ} \mathrm{Cmin}^{-1}$ to $30{ }^{\circ} \mathrm{C}$; the cycle was then repeated. Analysis of the data using TA Instruments" "Universal Analysis" software allowed determination of freezing and melting onset temperatures.

\section{RESULTS AND DISCUSSION}

During our investigations into the isomerisation of linear alkyl olefins, a range of C-18 linear isomerised olefin samples were prepared from $\alpha$-olefins, obtained from different suppliers, using several catalysts including alkali metal-alumina superbases, acid treated clays, zeolites, acidic polymer resins and organometallic reagents. The different catalysts, reaction conditions and olefin supplies led to a range of olefin isomer distributions, which are summarised in Table 1 along with the freezing temperatures of the olefins and the ASA products made from them.

Reaction progress was monitored by infrared (IR) spectroscopy, with a ratio of peak heights between the isomerised olefin and the vinyl $\alpha$-olefin of 9:1 determining sufficient isomerisation. This ratio is used as the quality control check on commercial samples of isomerised linear olefins that are used in ASA synthesis. Figure 1 shows the IR spectrum of a partially isomerised C-18 linear olefin that also contains vinylidene $\alpha$-olefin - the peak at $867 \mathrm{~cm}^{-1}$ is the vinylidene $\alpha$ olefin, $908 \mathrm{~cm}^{-1}$ is the vinyl $\alpha$-olefin and that at $964 \mathrm{~cm}^{-1}$ is the isomerised olefin. The 
isomerised:vinyl $\alpha$-olefin ratio is used as some olefin supplies do not contain vinylidene olefin. It should also be noted that the vinyl $\alpha$-olefin signal is somewhat more intense than the isomerised olefin signal, so the residual $\alpha$-olefin in at the end of the isomerisation reaction will be less than $10 \%$, though this cannot be quantitatively determined by IR.

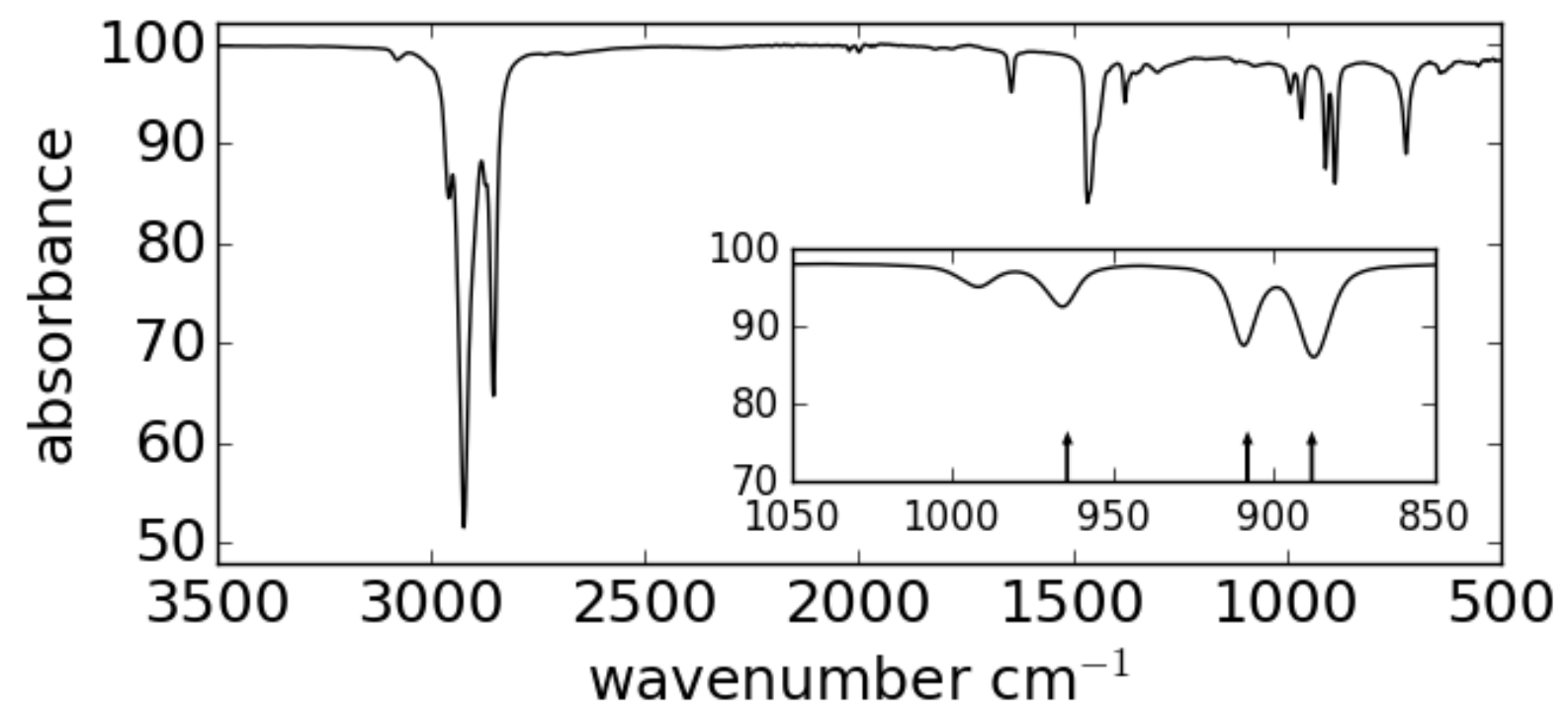

Figure 1. A representative IR spectrum of partially isomerised olefin showing vinyl $\alpha$-olefin, vinylidene $\alpha$-olefin and isomerised olefin peaks [reaction conditions: INEOS C-18 alpha olefin, Iron pentacarbonyl $\left.(0.15 \mathrm{~mol} \%), 150^{\circ} \mathrm{C}\right]$

The isomerised olefins were analysed using GC to characterise the isomer distributions; however, due to the minimal separation in boiling points of the isomers, they were not completely separated. The combination of the non-polar ZB-1/DB-1 column used in the GC (with a $100 \%$ dimethylpolysiloxane stationary phase) and the non-polar olefin samples results in separation of the compounds that is dependent only on their differences in boiling point - those with the higher boiling points giving peaks at longer retention times. 
As can be seen in Figure 2, there is some separation of peaks and some grouping of these peaks into regions. In an attempt to determine the identity of the peaks, we measured GC spectra on samples of olefin taken at various points in time during the progress of an isomerisation reaction. This analysis was performed on a reaction using an acid resin catalyst; in this reaction the olefin is isomerised in a stepwise fashion, ${ }^{17}$ so the first product to appear must be that with the double bond between the second and third carbon atoms on the chain ( $\alpha$-olefin has the double bond between the first and second carbon atoms). The $\alpha$-olefin starting material appears in Region B (see Figure 3), but as the reaction begins, peaks appear in Region A. As the isomerisation reactions progress, the intensities of Regions B, C and D begin to increase; we conclude that these regions are, therefore, due to the appearance of olefins with double bonds that are in progressively more internal positions along the chains. Shorter retention times for the more isomerised olefins seems plausible, as the shorter alkyl substituents on the double bond and greater distortion of the molecules should lead to more disruption of the packing of the molecules (and of the van der Waals' forces between them), and thus give a lower boiling point. Indeed, shorter retention times for more isomerised olefins have also been described in the work of Soják. ${ }^{5,6}$

Region $\mathrm{E}$ is due to branched isomers of the olefins. Again, the lower uniformity of the shape of the molecules gives rise to lower boiling temperatures. The branching of the olefins can arise from skeletal isomerisation during the reaction, ${ }^{18,19}$ or from isomerisation of vinylidene double bonds in the olefin feed - these are terminal dialkyl double bonds. The different olefin sources vary in their vinylidene olefin content. Not all catalysts isomerise these bonds, but the vinylidene bonds and the branched isomers all appear in Region E and do not affect the other regions of the GC trace. Region F, which appears at long retention times, seems very likely to be 
due to oligomeric olefin species (that are generally formed during acid catalysed isomerisation), while Regions $\mathrm{G}$ and $\mathrm{H}$ are due to $\mathrm{C}-16$ and $\mathrm{C}-20$ olefins, respectively; these are minor impurities in the olefin feed that remain from its manufacture (by ethylene oligomerisation). The oligomeric species are formed when two or more olefins react with each other to form larger molecules; for example, two C-18 olefins can react together to form a C-36 olefin species. These species are likely to have much higher boiling points and, hence, longer retention times on the GC column. Unfortunately, the GC method employed in this work does not have sufficient resolution to identify clearly the different oligomeric species that may be formed in a reaction.

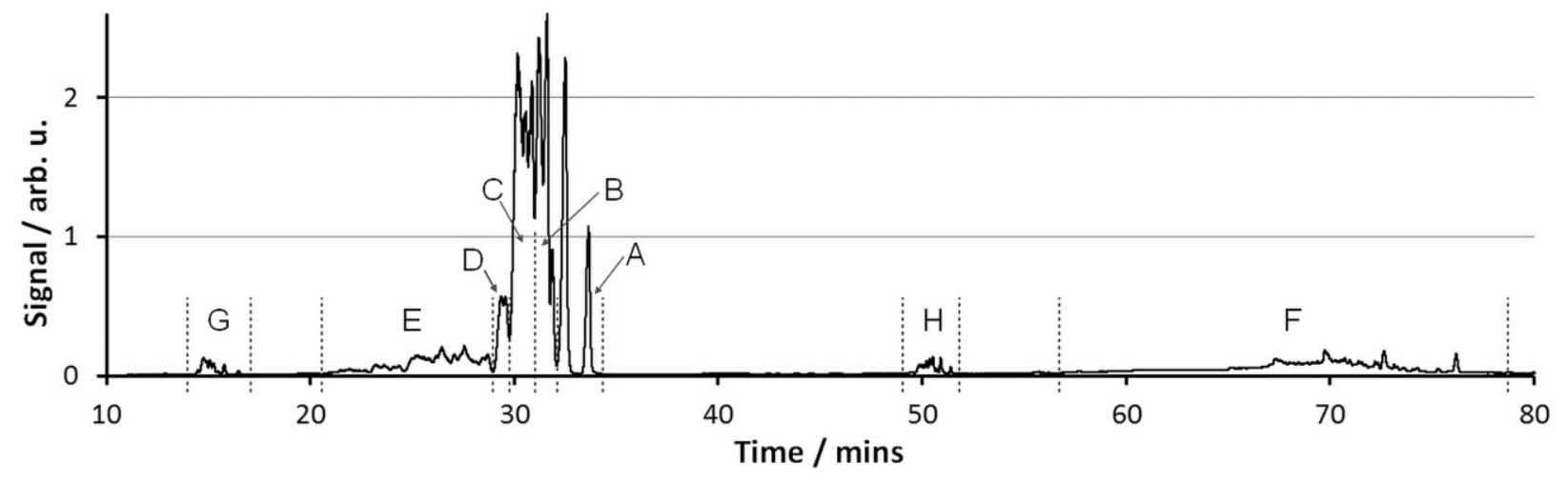

Figure 2. A representative GC spectrum of isomerised olefin [reaction conditions: Shell C-18 alpha olefin, Purolite CT151DR (2.3 wt\%), $\left.200{ }^{\circ} \mathrm{C}, 3 \mathrm{~h}\right]$ 


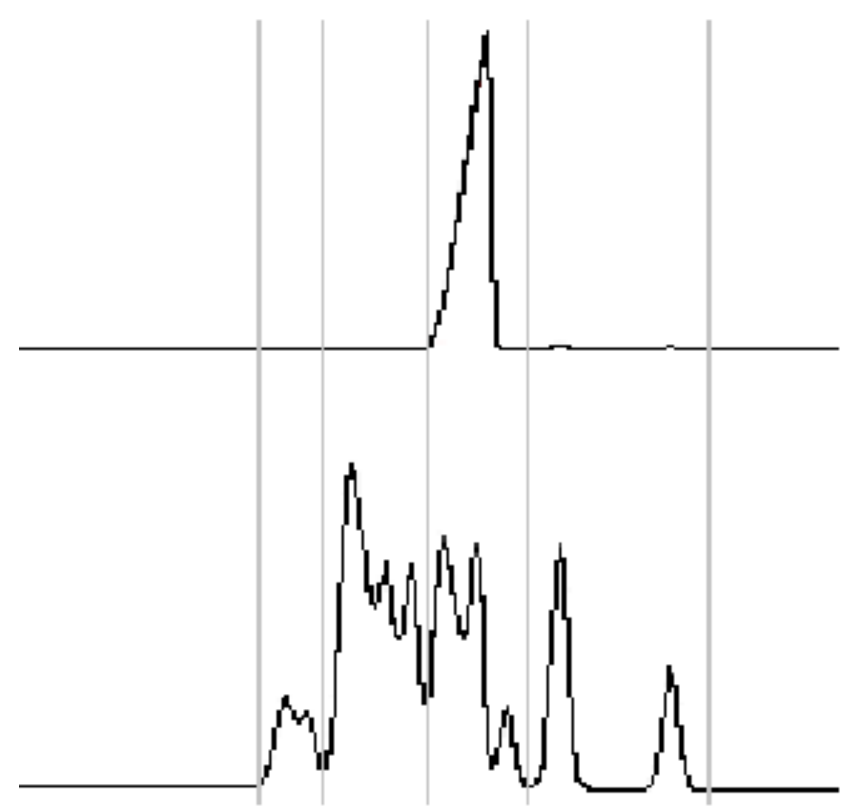

Figure 3. An expansion of Regions A-D in representative GC spectra of Shell $\alpha$-olefin (top) and isomerised olefin [reaction conditions: Iron pentacarbonyl $(0.15 \mathrm{~mol} \%), 150^{\circ} \mathrm{C}, 4.75 \mathrm{~h}$ ] (bottom)

\begin{tabular}{|c|c|c|c|c|c|c|c|c|c|c|}
\hline \multirow[t]{2}{*}{ Entry } & \multicolumn{8}{|c|}{ Olefin distribution (\%) } & \multirow{2}{*}{$\begin{array}{l}\text { Olefin } \\
\text { Freezing } \\
\text { temp } /{ }^{\circ} \mathrm{C}\end{array}$} & \multirow{2}{*}{$\begin{array}{l}\text { ASA } \\
\text { Freezing } \\
\text { temp } /{ }^{\circ} \mathrm{C}\end{array}$} \\
\hline & $\begin{array}{l}\operatorname{Reg} \\
\text { A }\end{array}$ & $\begin{array}{l}\text { Reg } \\
\text { B }\end{array}$ & $\begin{array}{l}\text { Reg } \\
\text { C }\end{array}$ & $\begin{array}{l}\text { Reg } \\
\text { D }\end{array}$ & \begin{tabular}{|l} 
Reg \\
E
\end{tabular} & $\begin{array}{l}\text { Reg } \\
\text { F }\end{array}$ & $\begin{array}{l}\text { Reg } \\
\text { G }\end{array}$ & $\begin{array}{l}\text { Reg } \\
\mathrm{H}\end{array}$ & & \\
\hline A & 65.7 & 25.2 & 0 & 0 & 5.5 & 0 & 0.9 & 2.7 & 9 & 13.25 \\
\hline B & 35.1 & 29.5 & 9.0 & 0.9 & 2.4 & 19.2 & 0.9 & 0.1 & 6 & 7 \\
\hline $\mathrm{C}$ & 19.7 & 28.9 & 20.0 & 2.0 & 2.3 & 24.5 & 1.4 & 1.3 & 1.75 & 0 \\
\hline $\mathrm{D}$ & 43.8 & 37.0 & 10.4 & 0.7 & 3.2 & 3.5 & 1.1 & 0.1 & 6 & 8.75 \\
\hline $\mathrm{E}$ & 10.2 & 21.0 & 38.3 & 6.7 & 17.4 & 2.7 & 1.3 & 2.7 & -10.5 & -17 \\
\hline $\mathrm{F}$ & 19.8 & 31.6 & 34.7 & 4.5 & 3.9 & 0 & 1.1 & 3.6 & -0.5 & -5 \\
\hline G & 19.2 & 23.0 & 9.5 & 0.3 & 19.8 & 24.6 & 1.1 & 2.5 & -3 & -3 \\
\hline $\mathrm{H}$ & 15.6 & 29.7 & 44.4 & 7.4 & 1.6 & 0 & 1.3 & 0 & -4.5 & -15.5 \\
\hline I & 11.2 & 19.9 & 30.7 & 4.5 & 24.9 & 0 & 1.5 & 7.5 & -11.5 & -16.5 \\
\hline
\end{tabular}

Table 1. GC data and freezing temperatures for a selection of olefins 
We expect that higher degrees of isomerisation should lead to lower freezing temperatures of the olefins. To determine whether this is the case, we plotted the isomer distributions against the freezing temperatures. In our initial assessments, it appeared that isomers in Region C showed good correlation with the freezing temperature of the olefin. However, as more samples of isomerised olefin were obtained, we realised that all of the more internal isomers (Regions C \& D) as well as branched isomers (Region E) and oligomers (Region F) contributed to the freezing temperature depression. A plot of the sum of the distributions for these regions against the freezing temperatures of the olefins gives good correlation, as shown in Figure 4.

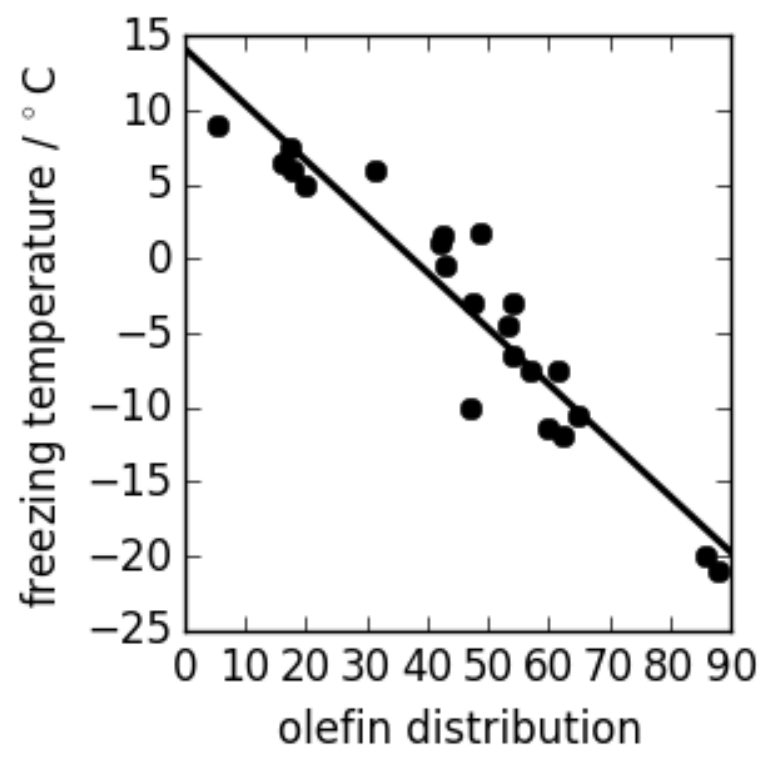

Figure 4. Variation of olefin freezing temperature with internal and branched olefin isomers and olefin oligomers (Regions C, D, E \& F). The circles are the experimental measurements and the solid line is a linear fit to the data $\left(y=-0.377 x+14.2, R^{2}=0.892\right)$

We applied the same analysis to the freezing temperatures of the ASAs derived from these isomerised olefin samples but found that the correlation was not as strong. However, when the olefin oligomer content is omitted, the correlation between the internal and branched olefin 
isomers and the ASA freezing temperature is very good (see Figure 5). We believe that this is because any oligomerised olefins are either removed along with unreacted olefin in the distillation step of the ASA synthesis or undergo the ene reaction with maleic anhydride to form a solid product that is incorporated in the mass that settles out/is filtered out of the bulk of the ASA, and so are not present in the sample whose freezing temperature is determined (some solid "char" is usually formed in ene reactions of olefins and maleic anhydride, and it is particularly noticeable on the lab scale reactions).

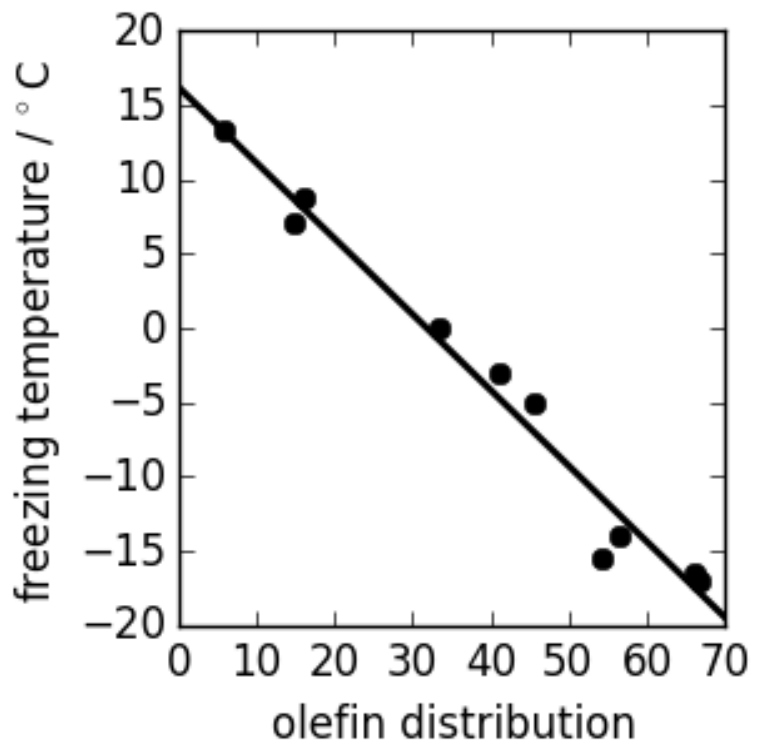

Figure 5. Variation of ASA freezing temperature with internal and branched olefin isomers (Regions C, D \& E). The circles are the experimental measurements and the solid line is a linear fit to the data $\left(y=-0.511 x+16.2, R^{2}=0.972\right)$

The freezing temperatures of the ASAs were also analysed using DSC. There is a stronger correlation between the melting onset temperature determined by DSC and the lab-measured freezing temperature than there is between the freezing onset temperature and the lab-measured freezing temperature; this correlation is shown in Figure 6. The discrepancy between the values 
of the freezing/melting temperatures, as determined by the two methods, arises from the differing rates of cooling (and heating) that the samples experience. In the DSC there is controlled cooling at a moderate rate, but in the lab freezing method the sample initially experiences a large temperature differential (there is about a $60{ }^{\circ} \mathrm{C}$ difference between ambient temperature and the cooling medium).

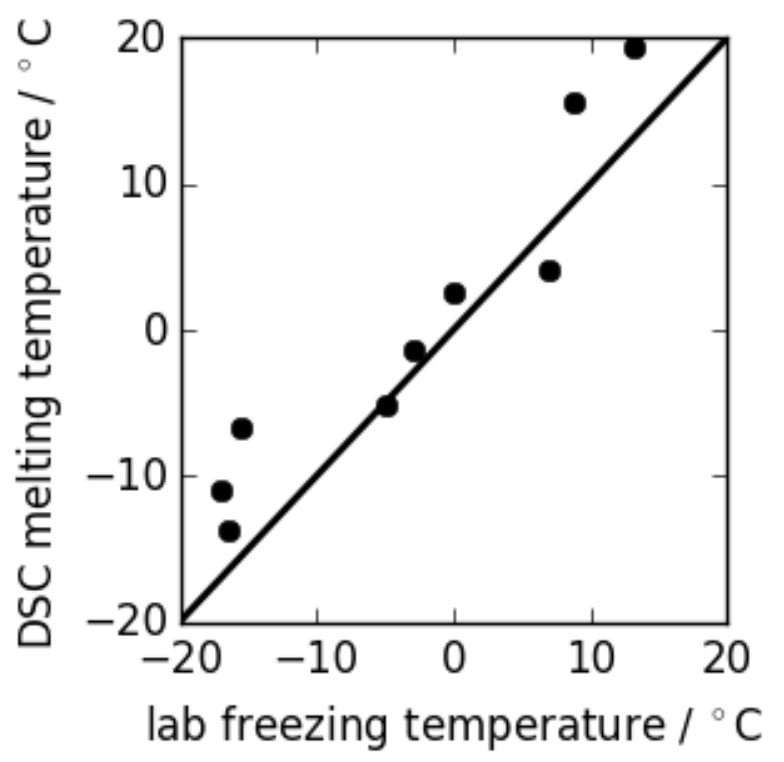

Figure 6. Comparison of the DSC-measured melting onset temperature with the lab-measured freezing temperature. The circles are the experimental measurements and the solid line denotes the case where both the DSC and lab measurements are identical

The differences between the two methods of ASA freezing temperature analysis (lab method/DSC) are negligible - both can be plotted against the internal and branched olefin isomers (Regions C, D \& E) on the same graph and the correlation remains good (see Figure 7). This provides strong evidence that the simple approach to freezing temperature measurement described herein is a robust method. Consequently, either method can be used for routine analysis of ASA freezing temperatures. 


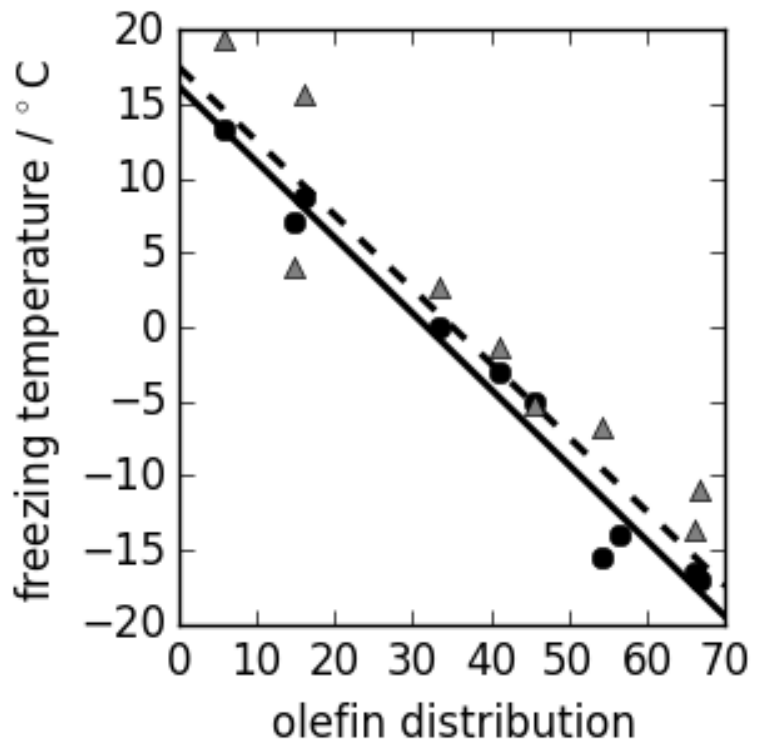

Figure 7. Variation of the freezing temperature of ASA with internal and branched olefin isomers (Regions C, D \& E). The black circles are the lab-measured freezing temperatures and the grey triangles are the DSC-measured melting onset temperatures. The solid line is the fit of the lab-measured data $\left(y=-0.511 x+16.2, R^{2}=0.972\right)$ and the dashed line is the fit of all the data $\left(y=-0.500 x+17.5, R^{2}=0.913\right)$

\section{CONCLUSIONS}

During our studies on the isomerisation of linear alkyl olefins we have developed a straightforward analysis of olefins based on their isomer distributions and freezing temperatures. The isomer distribution can be determined in a semi-quantitative manner by gas chromatography using a standard capillary column that is widely available and used commonly in the quality control labs of multi-purpose manufacturing sites. We have shown that the freezing temperatures of isomerised olefins and ASAs can be determined using simple laboratory apparatus if differential scanning calorimetry is unavailable. There is good correlation between the GC data for the olefin isomer distributions and the freezing temperatures of both the 
isomerised olefins and the ASAs made from them; this will allow prediction of the freezing properties of an ASA from a simple GC spectrum of the starting olefin, or the setting of a target olefin isomer distribution in order to achieve a desired ASA freezing temperature. While the methods described here do not pinpoint the exact isomer identities as some of the methods in the literature do, they do not require extra derivatisation steps or specialist equipment.

Consequently, they can be easily and practically employed in a busy manufacturing environment.

\section{AUTHOR INFORMATION}

\section{Corresponding Author}

* Philip B. Sellars. E-mail: p.sellars@warwick.ac.uk

\section{Present Addresses}

$\dagger$ WMG, International Manufacturing Centre, University of Warwick, Coventry, CV4 7AL, United Kingdom

\section{Notes}

The authors declare no conflict of interest.

\section{ACKNOWLEDGMENTS}

This work was supported by Innovate UK and Pentagon Chemical Specialties Ltd. as part of the Knowledge Transfer Partnership scheme - project number 9272.

\section{REFERENCES}

(1) Novak, R. W. Emulsification of alkenyl succinic anhydride sizing agents. US Patent 4,606,773, Aug 19, 1986. 
(2) Harrison, J. J.; Ruhe Jr, W. R. Two-step free radical catalyzed process for the preparation of alkenyl succinic anhydride. US Patent 5,286,799, Feb 15, 1994.

(3) Ramaswamy, R.; Sasidharan Achary, P.; Shine, K. G. Some aspects on the synthesis and characterization of dodecenyl succinic anhydride (DDSA) - a curing agent for epoxy resins. $J$. Appl. Polym. Sci. 1987, 33, 49-65.

(4) Zhang, W.; Liu, W.; Li, H.; Hubbe, M. A.; Yu, D.; Li, G.; Wang, H. Improving stability and sizing performance of alkenylsuccinic anhydride (ASA) emulsion by using melamine-modified Laponite particles as emulsion stabilizer. Ind. Eng. Chem. Res. 2014, 53, 12330-12338.

(5) Soják, L.; Ostrovský, I.; Kubinec, R.; Kraus, G.; Kraus, A. High-resolution gas chromatography with liquid crystal glass capillaries. J. Chromatogr. 1990, 520, 75-83.

(6) Soják, L.; Krupčík, J.; Janák, J. Comparison of capillary columns coated with $\mathrm{C}_{87}$ hydrocarbon and squalane in the analysis of $n$-pentadecene. J. Chromatogr. 1980, 191, 199-206.

(7) Gee, J. C.; Prampin, D. S. Method for determining double-bond positions in mixtures of linear olefins. Anal. Chem. 2009, 81, 1646-1651.

(8) Kwon, Y.; Lee, S.; Oh, D.-C.; Kim, S. Simple determination of double-bond positions in long-chain olefins by cross-metathesis. Angew. Chem. Int. Ed. 2011, 50, 8275-8278.

(9) Wheeler, T. F.; Heim, J. R.; LaTorre, M. R.; Janes, A. B. Mass spectral characterization of $p$ nonylphenol isomers using high-resolution capillary GC-MS. J. Chromatogr. Sci. 1997, 35, 1930.

(10) Chapman, L. R.; Kuemmel, D. F. Liquid-solid and capillary gas-liquid chromatography of internal olefin isomers. Anal. Chem. 1965, 37, 1598-1600. 
(11) ECHA, Helsinki. http://apps.echa.europa.eu/registered/data/dossiers/DISS-9c7eccdc-eb0f4d3f-e044-00144f67d249/AGGR-37787265-9729-4467-9d0d-205652201352_DISS-9c7eccdceb0f-4d3f-e044-00144f67d249.html\#AGGR-37787265-9729-4467-9d0d-205652201352 (accessed Oct 9, 2015).

(12) Reddy, C. M.; Nelson, R. K.; Sylva, S. P.; Xu, L.; Peacock, E. A.; Raghuraman, B.; Mullins, O. C. Identification and quantification of alkene-based drilling fluids in crude oils by comprehensive two-dimensional gas chromatography with flame ionization detection. $J$. Chromatogr. A 2007, 1148, 100-107.

(13) Ross, G. S.; Glasgow, A. R. A simplified freezing point apparatus. Anal. Chem. 1964, 36, $700-701$

(14) Phywe Systeme GmbH, Göttingen.

http://repository.phywe.de/files/bedanl.pdf/36821.00/e/3682100e.pdf (accessed Oct 5, 2015).

(15) Hoare, J. P. Freezing point measurement. J. Chem. Educ. 1960, 37, 146-147.

(16) Candy, L.; Vaca-Garcia, C.; Borredon, E. Synthesis and characterization of oleic succinic anhydrides: structure-property relations. J. Am. Oil Chem. Soc. 2005, 82, 271-277.

(17) Brouwer, D. M. The mechanism of double-bond isomerization of olefins on solid acids. $J$. Catal. 1962, 1, 22-31.

(18) Haag, W. O.; Pines, H. Alumina: Catalyst and support. III. The kinetics and mechanisms of olefin isomerization. J. Am. Chem. Soc. 1960, 82, 2488-2494.

(19) Corma, A. Inorganic solid acids and their use in acid-catalyzed hydrocarbon reactions. Chem. Rev. 1995, 95, 559-614. 
For Table of Contents Only

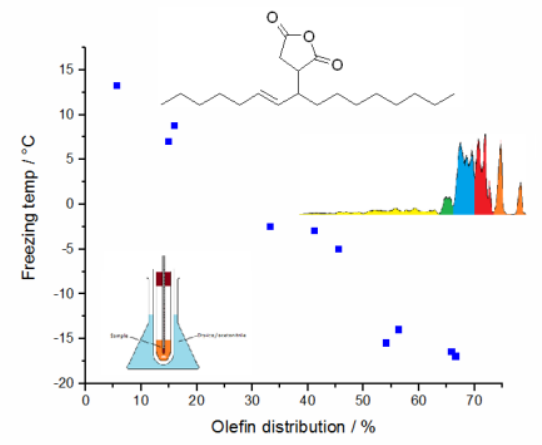

